\title{
Reflexos das políticas educacionais na gestão da escola e a complexidade
}

\author{
Francisca Eleodora S. Severino* \\ Izabel Petraglia* \\ Wellington Fernando Armandilha**
}

\section{Resumo}

O texto analisa a gestão da escola no âmbito das transformações estruturais em curso na sociedade contemporânea, levando em conta a complexidade polissêmica dessas transformações, a partir de pesquisa bibliográfica. Explicita também os elementos de reflexão e de formulação teórica para a compreensão dos contextos mais amplos: sociais, econômicos, culturais, políticos, legais que impactam as atividades dos profissionais da educação e delimitam suas condições de trabalho, seu papel na organização e gestão das atividades pedagógicas e administrativas da escola. $\mathrm{O}$ artigo estabelece o debate acerca dos sistemas e da legislação educacional, com ênfase no planejamento da educação, na cooperação federativa e no regime de colaboração entre os sistemas na educação. As reflexões se articulam de maneira transdisciplinar e consideram a perspectiva da teoria da complexidade, de Edgar Morin.

Palavras-chave: Gestão escolar; Sistemas de ensino; Planejamento educacional; Políticas educacionais; Complexidade.

* Doutora em Ciências da Comunicação pela USP. Mestre em Ciências Sociais pela PUCSP. Líder do Grupo de Pesquisa Educação Básica, Gestão e Inovação - Cadastrado no Diretório de Grupos do CNPq.

Contato: frasev@uol.com.br

** Doutora em Educação com Pós-Doutorado pelo Centre Edgar Morin EHESS/CNRS, Paris. Professora do Programa de Pós-Graduação em Educação da Universidade Metodista de São Paulo - UMESP e líder do Grupo de Estudos e Pesquisas em Complexidade - GEPEC, UMESP/CNPq.

Contato: izabelpetraglia@terra.com.br

*** Licenciado em Filosofia. Professor de História na Rede Estadual de Educação de São Paulo. Mestrando no PPGE na Universidade Metodista de São Paulo e Pesquisador do GEPEC - Grupo de Estudos e Pesquisas em Complexidade - UMESP/CNPQ. Contato: w_armandilha@hotmail.com 


\section{Reflections of educational policies in school ma- nagement and the complexity}

\section{Abstract}

The text analyzes the school management in the context of the structural changes taking place in contemporary society, taking into account the polysemic complexity of these transformations, based on bibliographic research. It also explains the elements of reflection and theoretical formulation to understand the broader contexts: social, economic, cultural, political, legal that impact the activities of education professionals and define their working conditions, their role in the organization and management of activities pedagogical and administrative aspects of the school. The article establishes the debate about educational systems and legislation, with an emphasis on education planning, federative cooperation and the collaboration system between systems in education. The reflections are articulated in a transdisciplinary way and consider the perspective of the theory of complexity, by Edgar Morin.

Key words: School management; Teaching systems; Educational planning; Educational policies; Complexity

\section{Reflexiones de las políticas educativas en la gesti- ón escolar y la complejidad}

\section{Resumen}

El texto analiza la gestión escolar en el contexto de los cambios estructurales que tienen lugar en la sociedad contemporánea, teniendo en cuenta la complejidad polisémica de estas transformaciones, basadas en la investigación bibliográfica. También explicita los elementos de reflexión y formulación teórica para comprender los contextos más amplios: sociales, económicos, culturales, políticos, legales que afectan las actividades de los profesionales de la educación y definen sus condiciones de trabajo, su papel en la organización y gestión de actividades. aspectos pedagógicos y administrativos de la escuela. El artículo establece el debate sobre los sistemas educativos y la legislación, con énfasis en la planificación de la educación, la cooperación federativa y el sistema de colaboración entre sistemas en educación. Las reflexiones se articulan de manera transdisciplinaria y consideran la perspectiva de la teoría de la complejidad, por Edgar Morin. Palabras clave: Gestión escolar; Sistemas de enseñanza; Planificación educativa; Políticas educativas; Complejidad 


\section{Introdução}

Entendemos que a educação deveria formar o cidadão consciente de seu papel na sociedade, indivíduo crítico, ético e complexo, que é ao mesmo tempo homo sapiens e homo demens. Entretanto, algumas políticas educacionais vão na contramão deste pensamento emancipatório, fazendo com que, muitas vezes, um sistema fragmentado tome conta e estruture a educação brasileira, em seus diversos níveis e graus.

Edgar Morin (2000a) nos apresenta um conjunto de sete saberes fundamentais que, juntos e em separado, cada um e todos, visam confrontar as limitações dos processos educacionais, sobretudo no que diz respeito à formação de sujeitos complexos, autores da própria história e construtores do universo socioeconômico, político e cultural de seu tempo. São saberes essenciais ao bem viver, que incluem atitudes ecologizadas e transformadoras do tempo e do espaço.

Entender que o processo educacional pode romper preconceitos, certezas obtusas e cristalizadas nos remete à urgência da reforma e ressignificação do pensamento para a religação, para o novo, para o complexo. Como afirma o autor: "Se soubermos compreender antes de condenar, estaremos no caminho da humanização das relações humanas". (MORIN, 2000a, p. 100).

Para Morin (2000b), religar saberes é um meio de romper com a fragmentação do conhecimento, mas, ele entende que tal processo não é simples e requer além de dedicação, uma ecologia da ação. Ou seja, se faz necessário que as práticas pedagógicas sejam constantemente revisitadas nas escolas a fim de não se hierarquizar saberes. Para Morin, o desafio está posto (2000b, p. 20): “A reforma do ensino deve levar à reforma do pensamento, e a reforma do pensamento deve levar à reforma do ensino". Pensar o aluno como um universo repleto de singularidades é fundamental para a reforma do pensamento e para a melhoria na gestão da escola, que leve em conta o conhecimento como meio de emancipação e, portanto, a educação como formadora de cidadãos responsáveis, críticos, criativos, planetários. 
Repensar a escola assim como a educação na atualidade é necessário. Temos a tecnologia digital e virtual cada vez mais presentes na vida das pessoas e reconfigurar o modo de ensinar e de pensar práticas de ensino-aprendizagem se torna crucial para a construção do conhecimento. A escola não pode ficar estagnada e deve promover a interação gestão-docente-discente, com vistas à formação científica e humanística.

Ao abordar a complexidade histórica em que se deu a emergência dos sistemas nacionais de ensino no Brasil, Dermeval Saviani (2010 p.380) assinala o caráter primitivo que o termo assumiu quando se trata de sua definição e de seu papel na gestão das políticas públicas da educação nacional. A generalização do uso da expressão "sistema de educação" leva educadores e gestores, responsáveis pelo planejamento escolar a uma espécie de desobrigação em compreender os processos e as relações que circunscrevem esse caráter primitivo, o que reafirma ambiguidades e imprecisões, dificultando, a definição do termo, tanto no âmbito do planejamento pedagógico quanto da gestão política. A consequência são os desvios nas ações daqueles profissionais que apostam na renovação dos métodos de gestão escolar, em prol de uma escola justa e igualitária.

Educadores e intelectuais refletem sobre as possibilidades de uma escola mais participativa e equitativa. Dentre eles, destacamos Marco Aurélio Nogueira (2001) ao expor o desafio de pensar a questão democrática frente aos processos de desenvolvimento globalizado. "Quem entre os educadores, já não se viu apostando nas possibilidades de uma renovação metodológica da gestão escolar que compensasse as falhas do sistema educacional, confrontasse as políticas governamentais e salvasse a escola, recuperando-a plenamente aos olhos da comunidade?" (NOGUEIRA. 2001, p.17).

Entendemos que todos os profissionais comprometidos com a educação responderiam positivamente a essa questão, reafirmando o compromisso com a escola e, consequentemente, com a cidadania. Entretanto, convergindo com a reflexão de Saviani, está também Carlos Nelson Coutinho (2002), que entende que um dos 
fatores para a dispersão e as ambiguidades no âmbito da gestão escolar no Brasil está

(...) no fato de que todos hoje se digam "democratas" não significa que acreditem efetivamente na democracia, mas sim que se generalizou o reconhecimento de que a democracia é uma virtude. Mas atenção para a hipocrisia: com extrema freqüência essa palavra, ainda que dita com ênfase, não significa, absolutamente, aquilo que nós socialistas, nós de esquerda, entendemos por democracia e nem sequer significa aquilo que a história da humanidade e o pensamento político entendem por democracia. (COUTINHO, 2002, p.12).

A conquista democrática no âmbito da gestão escolar se mostra como utopia em processo, e ela em sua função crítica, esclarece que o conceito de democracia se transforma e mostra seu caráter processual com características ideológicas acentuadas, de tal modo, que na atualidade o termo "democracia" assume a centralidade das discussões teórico políticas. Dito de outra forma, transformações deste conceito se fazem de acordo com as ideias de determinada época, e assim também, no presente momento de crise econômica.

A democracia na escola está atravessada por paradoxos e incertezas. A banalização da crise na escola pública se faz em nome de uma ideologia que hipervaloriza a educação escolar como caminho mais adequado ao êxito profissional e assim, é quase impossível visualizar saídas que não passem pela edificação de um sistema educacional e pela reinvenção da escola. (COUTINHO, 2002, p.17). Entretanto, a escola que temos reflete a impossibilidade administrativa resultante de políticas casuísticas praticadas nos últimos anos, com vista a ajustes reformistas da gestão escolar.

Sendo assim, como afirma Saviani, é urgente explicitar a noção de sistema em correlação ao conceito de estrutura, mostrando que em sua manifestação, no campo educativo brasileiro, ela vem carregada de sentidos ideológicos extemporâneos à escola nacional e às exigências contidas na noção de sistema educacional direcionado para as demandas da crise e da realidade brasileira. 


\section{Sistema nacional de educação: utopia ou realidade?}

A utopia está lá no horizonte. Me aproximo dois passos, ela se afasta dois passos. Caminho dez passos e o horizonte corre dez passos. Por mais que eu caminhe, jamais alcançarei. Para que serve a Utopia? Serve para isso: para que eu não deixe de caminhar. (GALEANO $\left.{ }^{1}\right)$.

A utopia democrática na modernidade foi incorporada às exigências da produção da economia liberal e, assim, essa integração foi o objetivo prático dos intelectuais e educadores que, consciente ou inconscientemente, se apoiaram nos esclarecimentos da racionalidade iluminista, do século XVIII. Isso ainda reverbera hoje, em graves embates e desafios, quando se trata de inovar a escola cumprindo a exigência de democratização social em tempos neoliberais. Eis porque diante da crise, falar em utopia implica em assumir uma intencionalidade pedagógica que, como a Utopia de Galeano, mesmo distante, instiga-nos a não abandonar a luta por sua conquista.

Considerar os obstáculos que vem impedindo a organização do sistema nacional de educação exige, antes de tudo, considerar as dificuldades que historicamente vem tornando utópica esta organização. Tal questão impõe a reflexão no eixo da relação passado e presente considerando que muitos fatos que circunscrevem a realidade hoje, foram no passado, considerados utópicos.

Para defender a validade da estratégia utópica é preciso exortar os educadores a irem além das fronteiras do que se mostra como realidade conhecida. Urge procurar fatos que estão às margens, à espera de serem decodificados e isto equivale a acreditar que a utopia está no processo da procura travestida de um caráter metodológico, cujo

Eduardo Galeano reproduz a resposta do cineasta Fernando Birri a um aluno que lhes perguntou: "Para que serve a Utopia?", no contexto da palestra proferida em Cartagena, numa Universidade local. (Ver: BOFF, L. O resgate das utopias e a função da religião. In: RODRIGUES, A. M. E.; WANDERLEY, L. E. W. (Orgs.). Utopia, ética, religião: a construção de um novo mundo. São Paulo: EDUC, 2019). Também disponível em: https://books. google.com.br/books?id=R_K7DwAAQBAJ\&pg=PT108\&lpg=PT108\&d$\mathrm{q} \# \mathrm{v}=$ onepage $\& \mathrm{q} \& \mathrm{f}=$ false $($ Acesso em 28/02/2020). 
efeito positivo está em nos levar além do que é conhecido. Assim é necessário refletir, a partir da contribuição de autores que, chamam a atenção para as confusões que ao longo do tempo, tem ocorrido no campo das políticas públicas e da gestão da escola, concomitantemente à produção econômica e social do mundo globalizado.

Em documento elaborado como subsídio à preparação da Conferência Nacional de Educação - CONAE, em 2010, Saviani (2010, p.380) reuniu elementos históricos e teóricos que pudessem auxiliar na compreensão da temática central referente ao Sistema Nacional de Educação bem como para fornecer esclarecimentos de alguns pontos obscuros no debate sobre o Plano Nacional de Educação (PNE), que naquele momento estava em vias de ser aprovado pelo parlamento nacional. Nesse documento, ele apresenta algumas indicações para a construção de um Sistema Nacional de Educação, articulando-o ao plano Nacional de Educação. Para tanto ele define sua compreensão de Sistema:

Se o sistema pode ser definido como a unidade de vários elementos intencionalmente reunidos de modo a formar um conjunto coerente e operante, conclui-se que o Sistema Nacional de educação é a unidade dos vários aspectos ou serviços educacionais mobilizados por determinado país, intencionalmente reunidos de modo a formar um conjunto coerente que opera eficazmente no processo de educação da população do referido país. (SAVIANI, 2010. p.381)

Dentre os principais obstáculos assinalados por Saviani para que se tenha um Sistema Nacional de Educação no Brasil, destacamos o obstáculo econômico que, a nosso ver, sintetiza e conduz toda discussão suscitada pela presença de outros obstáculos, também elencados e não menos importantes.

A reflexão provocada pelos argumentos do autor leva-nos à pergunta: existe um Sistema Nacional de Educação no Brasil? A resposta para tal pergunta aponta em síntese para duas dimensões condicionantes dos demais obstáculos que vem impedindo a real configuração do Sistema Nacional de Educação no país. 
Os obstáculos constituídos historicamente colocam em cena um divisor de águas entre os educadores. De um lado, a pergunta nos leva à crise geral do capitalismo global, cujos desdobramentos na vida econômica do desenvolvimento brasileiro condiciona, de modo alienante, os modos de vida e da política nacional; processo este que incide também nos modos da gestão escolar, impondo determinados comportamentos, antes de tudo, para a formação da mão de obra jovem para o mercado de trabalho. De outro lado, e em decorrência desse complexo processo alienante, muitos professores acreditam e advogam a existência de um sistema nacional de educação, visão equivocada da realidade, uma vez que não existe de fato um Sistema geral de educação no país.

\section{Crise de desenvolvimento e educação}

Os reflexos da crise de desenvolvimento global incidem na gestão das políticas públicas para a educação brasileira quando a escola se transforma em instituição direcionada a atender as demandas de mão de obra para o mercado de trabalho global. No âmbito da escola tudo se modifica, não apenas as relações entre educadores se transformam, mas também, a polifonia se instala sinalizando a produção do conhecimento, que se faz de forma alienada e subordinada ao desenvolvimento econômico neoliberal.

Ao buscar fundamentos para esclarecer tantas outras questões, Saviani (2010) faz aflorar vozes dissonantes e estas reafirmam o caráter primitivo de que o autor falara antes. De fato, a dissonância de discursos revela um jogo de palavras que coloca na ambiguidade a Constituição Nacional, de 1988.

É possível resumir os principais obstáculos apontados por Saviani à constituição de um Sistema Nacional articulado, mesmo que se tenha aprovado o Plano Nacional de Educação após intensa mobilização popular em prol de um Sistema educacional que garantisse uma educação democrática. Como já apontamos, o obstáculo que condiciona os demais é o fator econômico, pois é ele que justifica a persistente oposição à manutenção do ensino público. Intrin- 
secamente relacionado ao fator econômico, vem o obstáculo ligado à política e é igualmente importante pois reforça o primeiro. São fatores políticos expressos nas descontinuidades das iniciativas promotoras de reforma na educação. Outro obstáculo que não pode ser ignorado é o filosófico/ideológico. Este fator é promotor de um conhecimento de forte conotação alienante que defende ideias e interesses contrários ao sistema nacional de educação.

Saviani aponta ainda os obstáculos legais, dentre os quais destaca aqueles que são "materializados na resistência à incorporação da ideia de sistema nacional na nossa legislação educacional, cuja ponta de lança se ancorava na suposta e logicamente inconsistente tese da inconstitucionalidade da proposta de Sistema Nacional de Educação". (SAVIANI, 2010 p.381).

Aqui, educadores, intelectuais e ideólogos somam fileiras justificando um desenvolvimento conceitual que sustenta, mesmo que involuntariamente, interesses econômicos. Somado a tudo isso existem também entraves legais relacionados à resistência da aprovação de uma legislação que permita a organização do ensino de um real Sistema Nacional em nosso país. No geral, observamos que há menção explicita à articulação entre sistemas de ensino no país, todavia não é possível afirmar que o Brasil tem um Sistema Nacional de Educação articulado.

Refletindo sobre tais obstáculos, fica evidente que se optamos pelo recorte teórico que toma como paradigma reflexivo a base econômica e social, não há no Brasil um Sistema Nacional de Educação e este fato torna inviável a implementação positiva do Plano Nacional de Educação no país, a não ser que ele venha amparado por reformas, tais quais aquelas que temos observado na atual Lei de Diretrizes e Bases (LDB). "É necessário fortalecer a resistência contra as ações "legalistas", por meio das quais são provocadas mudanças estruturais na $\mathrm{LDB} / 96$ e impactam negativamente a formação e a valorização dos profissionais do magistério". (BRZEZINSKI, 2018, p.104).

Embora se reconheça o grande esforço dos educadores em assumir e validar este plano, que até o momento não vai muito além 
de uma utopia em processo, nem todos eles concordam com o diagnóstico de que também a escola está subordinada ao desenvolvimento da economia global, sofrendo nas entranhas os efeitos da crise geral. E, Mesmo que identifiquem os efeitos perversos dessa crise global, intelectuais abstraem o caráter econômico de suas análises e conduzem a reflexão para o campo cultural. Eles compõem o grupo de ideólogos e argumentam que estando a educação determinada pela produção do conhecimento cultural, ela estaria acima e ao resguardo da crise de desenvolvimento econômico global.

Com esse recorte conceitual, entendemos que o problema seria mais facilmente resolvido com a melhoria da qualidade do ensino e da pesquisa no país. Para muitos, os males da escola derivam da má formação de seus professores. Mas, a má formação já é consequência de uma redistribuição de bens culturais desigual que coloca de um lado a escola insuficiente com um currículo mínimo para os pobres, e uma escola de qualidade para os ricos, na qual a produção dos saberes se faz a partir de uma formação sólida em conhecimentos e bens culturais.

É fato que uma boa formação profissional direcionada aos professores e gestores possibilita a gestão democrática da escola com redistribuição igualitária do conhecimento, seja para ricos, seja para pobres. Entretanto para que alcancemos uma boa formação para professores, é necessário antes, compreender o processo que os coloca à margem de uma formação de qualidade democrática, à vista que mais e mais sofremos os efeitos do desenvolvimento econômico que vem se beneficiando enormemente da ciência tecnológica e de informação, fatores que beneficiam muito a concentração de renda e a economia global.

\section{Estrutura e organização do sistema de ensino em âmbito Federal, Estadual, Municipal}

É consenso que a educação brasileira está em crise e que precisamos reformar a escola e, em consequência, o Sistema educacional que até o momento se apresenta como utopia. Disto decorre 
que para além de reavaliar o Sistema Nacional de Educação necessitamos de novas políticas e incentivos e, é aqui que esbarramos no principal desafio, pois isto implica em mobilizar energias para dinamizar a escola e a educação, tanto a partir de dentro quanto a partir de fora.

O que isto significa?

Que no Brasil, não há como avaliar a escola, torná-la acessível para todos e ser realmente democrática se a reflexão não se detiver nos seus aspectos mais profundos de desenvolvimento econômico local, na sua relação direta com a economia global.

Sendo assim, existe o compromisso de pensar a educação no Brasil, em tempos de globalização neoliberal e, em consequência, pensar também as condicionantes das políticas de educação em suas múltiplas articulações. Esta é a questão crucial que condiciona a resolução de parte dos obstáculos e, historicamente, vem impedindo a organização do sistema educacional. Não se trata aqui de retomar, reiterar os obstáculos amplamente discutidos por Saviani (2010), mas, trata-se de buscar a raiz de onde decorre o problema em tela.

Mesmo antes da promulgação da LDB/96, como esclarece Palma Filho (2005), a educação inicia um intenso processo de reforma, ao mesmo tempo que outros setores do campo governamental também são reformados em seu funcionamento.

Quando se trata de iniciativas estaduais, as inovações curriculares predominam nos anos de 1980, enquanto nos anos de 1990 sob a gestão e liderança da presidência de Fernando Henrique Cardoso, o Brasil passa a se adequar ao ajuste econômico, acertado com os organismos internacionais. É assim, que se consolida, na década de 1990, a iniciativa federal com vistas a facilitar estes ajustes. Para tanto, o governo conta com o apoio do Ministério da Educação (MEC) que fora reformado com o objetivo de respaldar as reformas exigidas no processo. Assim, naquele momento, as novas atribuições conferidas ao MEC pela LDB, Lei Federal 9.394, de 1996, artigo 9, consolidam a tendência de centralização das ações na esfera federal. 
Mesmo um ano antes da promulgação da LDB, a Lei Federal número 9.131, em 1995, alterava os dispositivos da Lei Federal 4.024 de 20/12/1961. Tal alteração tinha por objetivo conferir ao MEC o papel elaborador e coordenador da política educacional brasileira. Ao mesmo tempo, essa Lei atribuía ao MEC a função de ser o principal gestor da política de avaliação nacional.

Ainda de acordo com a reflexão de Palma Filho (2005), pela Lei Federal 9.131/95, criava-se o Conselho Nacional de Educação (CNE) em substituição ao Conselho Federal de Educação (CFE) com competências e atribuições reduzidas. O CNE é um órgão de assessoramento do Ministério da Educação, cuja competência diz respeito à aprovação de diretrizes curriculares para os diferentes níveis de educação nacional, inclusive em relação à educação profissional. As diretrizes ali aprovadas são implementadas no âmbito dos Sistemas Estaduais e Municipais de Educação.

Abordar os princípios estabelecidos pela LDB/96, bem como as ações que buscavam construir um Sistema Nacional de Educação articulado, parece ser uma maneira de chegar à finalidade de conhecer a estrutura e a organização do Sistema de ensino nos âmbitos federal, estadual e municipal. Todavia, deve-se conhecer também os níveis e as modalidades de educação e ensino, o financiamento da educação e o programa de assistência ao estudante do Fundo Nacional de Desenvolvimento da Educação (FNDE).

O significado de Sistema se expande, então, para além do conjunto de escolas e para o órgão administrador que os comanda, colocando algumas definições que possuem pontos comuns de Sistema, o que, no entanto, não confirma que elas dão o perfil de um aparelho mais amplo como é o caso do Sistema Nacional, estando ele acima da estrutura formada por sistemas menores, um conjunto de elementos interligados.

Desse modo, Sistema Nacional pode ser definido como explica Saviani (2010) como sendo uma disposição de partes do todo coordenadas entre si. É um conjunto de ações e de instituições políticas e/ou sociais, de métodos por elas adotados. Tais elementos 
materiais e ideais, instituições e métodos coordenados entre si, não perdem suas especificidades e individualidades apesar de integrar um todo organizado. Do mesmo modo, o conjunto de normas e leis que regulam a organização não perdem sua identidade legal.

Tem-se inúmeros exemplos de sistemas menores articulados entre si, tais como os sistemas: religioso, econômico, político, cultural, jurídico etc. Exemplo de articulação complementar ou administrativa é quando os sistemas de ensino recebem recursos do Estado para serem gastos nas escolas e, nesse caso ocorrem ações entre o sistema de ensino e demais sistemas afins como o sistema político, o sistema econômico. O enfrentamento das reações se alterna em razão da articulação de outros componentes presentes nos sistemas, além de maneiras diversas de lidar com outros sistemas em geral.

Há duas formas de construção, organização e funcionamento de um sistema. Na primeira modalidade que é adaptativa, são realçados aspectos estáveis e harmoniosos da organização. A justificativa para isto deriva da teoria funcionalista, na qual a estabilidade é assegurada pela adaptação. Mas, quando se trata de educação, as questões adaptativas podem ser superadas se as compreendemos como resultado de ações autoritárias derivadas de diagnósticos realizados sob um ponto de vista que desconhece as questões relacionadas às diferenças sócio culturais.

No mundo cada vez mais complexo e globalizado, com grandes avanços informacionais disponíveis para todos os ramos do conhecimento, não se compreende a gestão das ações pedagógicas realizadas sem a efetiva participação de todos os membros envolvidos. O caráter dinâmico ou a possibilidade de mudança do sistema se justifica na contradição do processo em que se insere.

Sobre a articulação e religação de saberes, a gestão das ações pedagógicas se impõe a partir do Projeto Político Pedagógico (PPP). Fala-se muito sobre escola democrática, no entanto cabe elucidar que em consonância com a LDB/96, muitos esforços são direcionados para a democratização das relações escolares. Todavia, apenas uma difusa existência de mecanismos democratizantes no interior da es- 
cola ou no discurso proferido pelos dirigentes não demonstram que existe uma gestão democrática. Ressalta-se que um destes mecanismo de importância fundamental é o PPP por prever em seus estatutos a presença da comunidade na qual se insere a escola.

Isoladamente e sem apoio governamental, esses mecanismos passam meramente a cumprir normas burocráticas e não promovem uma reflexão vigorosa que ultrapasse os muros da própria escola e permeie a sociedade, a começar pelos lares dos muitos estudantes envolvidos com esses mecanismos. (SEVERINO; AMORIM, 2018, p. 117).

A reflexão das autoras aborda a precária existência do PPP quando analisam a implementação dele em algumas escolas escolhidas para referenciar empiricamente o desenvolvimento de uma pesquisa. Referindo-se à equipe gestora, embora reconhecendo a possibilidade de alguma exceção no que tange ao PPP, elas afirmam: “(...) elaboram-no apenas para o cumprimento das determinações da Lei 13.005, de 25 de julho de 2014 que, no seu artigo $2^{\circ}$, inciso VII, esclarece as diretrizes para a promoção humanística, científica, artística / cultural e tecnológica do país." (SEVERINO; AMORIM, 2018, p.117).

Morin corrobora essa ideia e ainda resgata as práticas pedagógicas quando afirma que “(...) em nossas escolas, em nossas universidades, certamente nos ensinam a compreender as coisas, mas elas são separadas, isoladas. Não somos ensinados a religá-las e, portanto, a enfrentar nossos problemas fundamentais, globais”. (MORIN, 2010, p. 216). Essa realidade local também se faz presente no macro sistema educacional do País.

Morin reconhece limites e incertezas, mas, aposta na esperança de uma reforma do pensamento e das instituições, como caminho possível e necessário e, entende que sempre há de haver uma brecha ou bifurcação (1999, p. 41): “A missão deste método não é fornecer as fórmulas programáticas de um pensamento 'são', mas convidar a pensar-se a si mesmo na complexidade". Esse exercício de reflexão a que nos convida o autor remete-nos ao paradoxo de 
desafios e possibilidades das políticas educacionais no Brasil, em suas múltiplas perspectivas.

\section{Considerações finais}

Considerando as reflexões sobre as políticas educacionais na gestão da escola e, seus impactos sobretudo no sistema nacional de educação, um novo olhar voltado à cidadania se faz necessário. Morin $\left(1999 ; 2000^{a}\right.$; 2000b; 2010) propõe a religação das mais diversas áreas do saber por meio da transdisciplinaridade, o que denota a experiência de ir além do que se vê através e entre as práticas e as ideias de ensino e de gestão. A complexidade nos conduz à ideia do que é tecido junto: as partes e o todo, o uno e o múltiplo, o local e o global, o micro e o macro sistema, e compreende a importância das articulações entre fatores internos e externos de influências e o rompimento com o pensamento fragmentado e excludente.

As ideias de Morin presentes em Os Sete Saberes necessários à educação do futuro $\left(2000^{\mathrm{a}}\right)$ podem contribuir para a reflexão das políticas educacionais, assim como para a concepção de cidadania que se deseja e, essas ideias nos direcionam a uma ressignificação das práticas educacionais, tanto na docência quanto na gestão escolar e educacional, em seus sistemas mais abrangentes e complexos, que visam a formação do indivíduo, a partir de pressupostos epistemológicos, metodológicos e ontológicos.

Como se viu, as questões relativas ao Sistema Nacional de Educação são bem mais complexas do que possamos avaliar num primeiro momento. Contudo, como Galeano explicita, é necessário que se saiba que a utopia é uma caminhada ou um processo de busca. É forçoso compreender que num contexto social de crise, de fato, a utopia não é um objetivo, é sim uma caminhada a procura de possíveis saídas e, como tal, tem uma função crítica e consequentemente pedagógica. Se compreendida desta forma, a utopia pode ser vista como método que coloca à disposição o clarão da esperança que ilumina os nexos mais profundos da realidade e com isso desbrava novos caminhos. 
Se a utopia de uma escola justa e democrática for compreendida como método pedagógico de intervenção num processo social complexo, ela terá a função precípua de iluminar o contexto histórico em que se apresentam as relações que firmam a articulação entre Sistema Nacional de Educação e estrutura política, que como afirma Saviani (2010), ensejam ambiguidades e generalizações obscurecendo a realidade social, de tal modo que no campo das relações que buscam a construção democrática da escola, o termo Sistema parece não necessitar de definição.

Nessa acepção difusa e controversa que marca o contexto da luta por democracia na escola, o termo sistema se revela polissêmico e prenhe de ambiguidades fazendo com que a gestão pedagógica também se revele em crise. Nessas condições, falar de utopia implica, pois, assumir um método e uma intencionalidade pedagógica. À luz da esperança utópica busca-se então exortar os profissionais da educação a validar a estratégia e o método utópico na busca de superação da crise.

\section{Referências}

ALMEIDA, M. da C. de e CARVALHO E. (Orgs.). Edgar Morin. Educação e Complexidade: Os Sete Saberes e outros ensaios. São Paulo: Cortez, 2005.

BRASIL. Constituição (1988). Constituição da República Federativa do Brasil. Disponível em: < http://www2.camara.leg.br/legin/fed/consti/1988/constituicao-1988-5-outubro-1988-322142-publicacaooriginal-1-pl.html>. Acesso em: 21 maio 2019.

BRZEZINSKI, I. Formação dos profissionais do Magistério na LDB/1996: entre os projetos educacionais e antagônicos. In: BRZEZINSKI, I. (org.) LDB/1996: Vinte anos depois. Projetos educacionais em disputa. São Paulo: Cortez, 2018. (p. 95-129).

COUTINHO, C. N. A democracia na batalha das ideias e nas lutas políticas no Brasil de hoje. In: FÁvero, O. \& SEMERARO, G. (Orgs.). Democracia e Construção do Público no pensamento educacional brasileiro. Petrópolis: Vozes, 2002. 
FRIGOTTO, G. Estrutura, sujeitos e os fundamentos da relação trabalho e educação. In: LMBARDI, J. C; SAVIANI, D.; SANFELICCE, J. L. Capitalismo, Trabalho e Educação. Campinas, SP: Editora Autores Associados, 2002.

LIBÂNEO, J. C.; OLIVEIRA, J. F. de; TOSCHI, M. S. Estrutura e organização do ensino brasileiro: aspectos legais e organizacionais. In: Educação escolar: políticas, estrutura e organização. 10 ed. São Paulo: Cortez, 2012. (p. 307-370).

MORIN, E. Meu caminho. Entrevistas com Djénane Kareh Tager. Trad. Edgard de Assis Carvalho e Mariza Perassi Bosco. Rio de Janeiro: Bertrand Brasil, 2010.

Os sete saberes necessários à educação do futuro. Trad. Catarina Eleonora F. da Silva e Jeanne Sawaya. São Paulo: Cortez; Brasília: Unesco, 2000a.

- A cabeça bem-feita: repensar a reforma, reformar o pensamento. Trad. Eloá Jacobina. Rio de Janeiro: Bertrand Brasil, 2000b.

Complexidade e transdisciplinaridade: a reforma da universidade e do ensino fundamental. Trad. Edgard de Assis Carvalho. Natal: Editora da UFRN, 1999.

NOGUEIRA, M. A. Prefácio. In: SOARES, R. D. Gramsci, o Estado e a escola. Ijuí: Ed. Univ. Ijuí, 2001.

PALMA FILHO. J. C. Política Educacional Brasileira. São Paulo: Editora CTE, 2005.

SANDER, B. O estudo da administração da educação na virada do século. In: MACHADO, L. M. \& FERREIRA, N. S. (Org.). Política e gestão da educação: dois olhares. Rio de Janeiro: DP\&A Editora; ANPAE, 2002. (p.55-68).

Gestão da educação na América Latina. Construção e reconstrução do conhecimento. Campinas: Autores Associados, 1995.

SAVIANI, D. Documento: Sistema Nacional de educação articulado ao Plano Nacional de Educação. In: Revista Brasileira de Educação v. 15 n. 44 maio/ag. 2010. (p. 380-412).

SEVERINO, F. E. S.; AMORIM, K. B. P. G. A relevância da gestão democrática escolar. Anais do V Seminário Regional ANPAE: Políticas públicas como campo de disputas - Passo Fundo. 2018. 
TEODORO, A. JEZINE, E. (Org.) Organizações internacionais e modos de regulação das políticas de Educação: indicadores e comparações internacionais. Brasília: Liber Livros, 2012.

VEIGA, I. P. A. (Org.). Projeto Político Pedagógico da Escola: Uma Construção Possível. Campinas, SP: Papiros Editora, 2014. 